\title{
PHASE EQUILIBRIUM OF PETROLEUM DISPERSION SYSTEMS IN TERMS OF THERMODYNAMICS AND KINETICS
}

\author{
Olena Tertyshna ${ }^{1}{ }^{\otimes}$, Konstantin Zamikula ${ }^{1}$, Oleg Tertyshny ${ }^{1}$, Olena Zinchenko ${ }^{2}$, \\ Petro Topilnytskyi ${ }^{3}$
}

https://doi.org/10.23939/chcht15.01.132

\begin{abstract}
The process of paraffin formation has been considered, including the peculiarities of the paraffin structure as a result of phase transitions with a decreasing temperature. Mathematical models for thermodynamic and kinetic calculations of the "solid-liquid" system phase equilibrium have been developed. To shift the "fuel oilparaffin" balance towards the liquid, it is necessary to reduce the activity ratio of solid and liquid phases by introducing into the system a substance with a lower solubility parameter. To increase the stability, as well as structural and mechanical characteristics of fuel oil, the additive of plant origin was synthesized. The phase transitions in fuel oil depending on the temperature when adding different amounts of additives have been studied.
\end{abstract}

Keywords: phase equilibrium, mathematical model, thermodynamics, kinetics, additive, fuel oil, paraffin, crystals.

\section{Introduction}

Phase transitions of paraffinic hydrocarbons in petroleum products occur due to the changes in thermobaric conditions and are accompanied by the generation of complex spatial structures, which form solid deposits on cooling. The results are the losses of hydrocarbons, the deterioration of the equipment performance and ecological state of the environment. Knowledge of the phase transformation laws and the ability to predict them allow to increase the efficiency of oil refining, to design the optimized technological schemes, to provide trouble-free transportation, storage and operation of oil products.

\footnotetext{
${ }^{1}$ State Higher Educational Institution "Ukrainian State University of Chemical Technology"

8, Gagarina Ave., 8, 49005, Dnipro, Ukraine

${ }^{2}$ PJSC "Ukrtatnafta", 3, Svishtovska St., 39610 Kremenchuk, Ukraine

${ }^{3}$ Lviv Polytechnic National University,

12, Bandery St., 79013, Lviv, Ukraine

t_elena2000@bigmir.net

(c) Tertyshna O., Zamikula K., Tertyshny O., Zinchenko O., Topilnytskyi P., 2021
}

From a practical point of view, the most important task is to diagnose the initial stages of paraffin crystallization and develop effective methods of inhibiting this process. It can be assumed that the experimental approach, which combines traditional physico-chemical research methods and mathematical modeling, will not only advance the understanding of the process basic laws, but will also create a scientifically sound method of this process control. This fundamental task, which is relevant for practice, has not been completely solved [1-3].

The first works in this direction were devoted to modeling a three-phase system "oil-gas-paraffin" [4]. The author believed that the primary factor in paraffin formation is the presence of gas phase in oil, which intensifies the growth of paraffin granules and increases the rate of paraffin deposits formation.

The basis of the diffusion mathematical model according to Musakaev [5] is a crystallization mechanism of paraffin formation, when the formation and subsequent growth of paraffin deposits occur due to the growth of crystals directly on the surface of the equipment. The paraffin crystallization is presented as "sticking" of singlecrystal structures on the cooled surface. However, the deposition of paraffin from the solution is much more complicated and requires more detailed mathematical modeling.

Based on numerical modeling of non-isothermal filtration of multicomponent oil, Sarafutdinov [6] showed that during crystallization of the system there are several fronts of phase transitions. However, in this work a rather important assumption is applied: all components of the system can be in only three "discrete states" (gas, oil, paraffin) but the phase state near the saturation line is not taken into account.

The equation of phase equilibrium in the system "gas-oil" was studied by Brusilovsky [7], who described the calculation scheme of a multicomponent system in detail with changes in pressure and temperature. The author believes that the development of methods for composite modeling of multicomponent systems filtration leads to the use of Van der Waals type equations to describe the thermodynamic properties of natural 
hydrocarbon mixtures. However, he does not include in the system of equations the processes associated with phase transitions to the solid state, i.e. crystallization of macromolecular compounds.

Based on a multivariate equilibrium model for predicting paraffin formation Ortega-Rodrigues et al. [8] estimated the melting point of pure components, including normal paraffin, naphthenic and aromatic hydrocarbons. The correlation between the enthalpy of melting and the change in a specific heat between the solid and liquid phases based on the Pedersen equation has been proposed [9]. However, the phase transition time of solids is ignored when calculating the volatility of solid and liquid phases for pure components.

In [10] for the first time, the prediction of paraffinization process is represented by several mathematical models of equilibrium using the coefficients of activity components in the solid and liquid phases. The algorithm for calculating the phase equilibrium constant in the "liquid-paraffin" system is carried out due to the fugitives of individual components. However, to determine the main parameters included in the calculation, semiempirical dependences are taken and only thermodynamic equilibrium is estimated without taking into account the kinetics of nucleation and the growth of paraffin crystals.

Based on the analysis of literature data, the mechanism of paraffinization is reliably described by the concepts of molecular thermodynamics, which are based on the basic thermodynamic potentials of the phase transition, taking into account the component composition of the system. The phase transition takes into account the existence of two allotropic forms of crystals, which are formed during the crystallization of solid components (each with its own constants of phase transitions).

A promising method of preventing paraffin formation is the use of chemical reagents-inhibitors which change the crystal structure of paraffins at the moment of the solid phase origin with the decrease in temperature. Despite the extensive research of petroleum dispersed systems the interaction of paraffin crystals of different structures with the reagents used to regulate the structural and mechanical properties, including their stability, are insufficiently studied.

Modern requirements for reagents designed to prevent the crystallization of paraffins and their deposition, include their universality. As world and domestic experience shows, one of the promising ways to increase the efficiency of deposits prevention is the use of composites. However, there is no methodology for the compounds selection and the development of such reagents is carried out mainly empirically, by testing on a narrow range of objects without taking into account physico-chemical phenomena occurring in the reagentpetroleum product system. Another complication is that the processes are heterophase and non-equilibrium. A majority of inhibitors has a lot of disadvantages: high cost, the presence of toxic components, instability of their effect regarding a wide range of petroleum products.

The aim of this study is to develop a mathematical model for thermodynamic and kinetic calculations of phase transitions in petroleum dispersed systems (PDS), experimental identification of factors affecting the rate of solid phase accumulation and determination of paraffin inhibitor optimal concentration.

\section{Experimental}

A significant resource for regulating the structural and mechanical characteristics of high-boiling petroleum products are reagents of plant origin, the relevance of which is substantiated by their restorability, low cost, ecofriendliness and the possibility of involvement in the hydrocarbon system due to their compatibility [11-13].

\subsection{Additive Synthesis}

The synthesis of the additive, based on diglycerides of fatty acids, was carried out using a glycerol-containing fraction which is a by-product of biodiesel production. After purification and preparation the glycerol esters were obtained via transesterification of rapeseed and castor oils in the presence of potassium hydroxide according to the $\mathrm{S}_{\mathrm{N}} 2$ mechanism.

The initial technical glycerol-containing fraction $(52 \mathrm{~g})$ contained $54.3 \mathrm{wt} \%(0.3 \mathrm{~mol})$ of glycerol, $35.5 \mathrm{wt} \%$ of methanol and $10.2 \mathrm{wt} \%$ of $\mathrm{KOH}+$ soap. Before the synthesis methanol was distilled off and the soap was separated. The purified glycerol-containing fraction ( $99.5 \mathrm{wt} \%$ of glycerol) was heated to $273-293 \mathrm{~K}$, and then $0.7 \mathrm{~g}$ of $\mathrm{KOH}$ was dissolved in it. $540 \mathrm{~g}$ of a rapeseed and castor oils mixture $(8: 2)$ were added, which corresponded to the molar ratio of glycerol:oil $=1: 2$. To remove the water formed in the reactor, toluene as an azeotropic agent $(50 \mathrm{~g})$ was added. The reaction mass was stirred vigorously at $413-418 \mathrm{~K}$ for $5 \mathrm{~h}$.

The mechanism of additive synthesis may be represented as follows [14]:

1) Formation of nucleophilic active compound - potassium glycerate

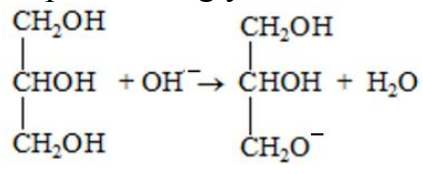


2) Substitution of fatty residue for glyceride according to the mechanism $S_{N} 2$

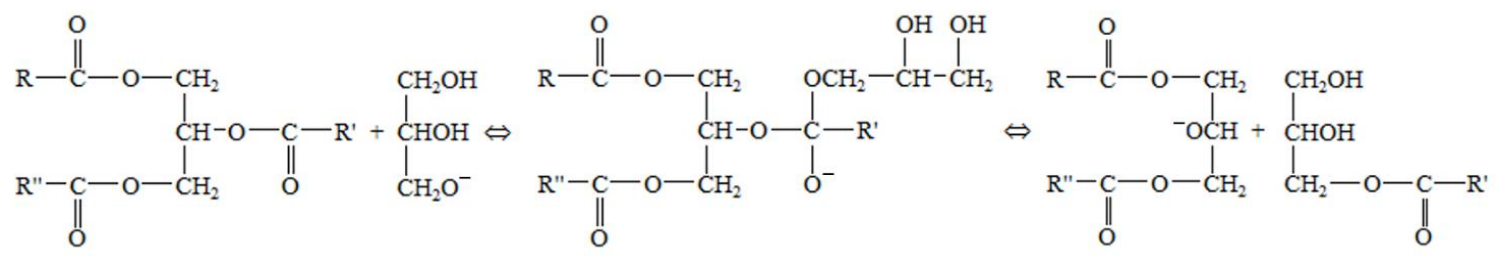

3) Catalyst recombination<smiles></smiles>

The unreacted lower layer of glycerol was separated together with the alkali by means of a separating funnel. To saponify the free fatty acids formed during the side reactions, the reaction mass obtained after distillation of toluene was neutralized with $10-15 \%$ sodium bicarbonate solution and washed with water. From the liquid obtained after washing, esters of glycerol were isolated by vacuum distillation at a residual pressure of $1.33-2.0 \mathrm{kPa}$.

\subsection{Testing of the Synthesized Additive}

\subsubsection{Methods for determining the additive composition and its physico-chemical properties}

The composition of the synthesized additive was determined by HP 6890 gas chromatograph with a flame ionization detector manufactured by HewlettPackard.

Since the gas chromatograph is not designed to analyze glycerides of fatty acids, the samples were subjected to transesterification with methanol according to [15]. For this purpose, 2-3 drops selected by a pipette were diluted in $1.9 \mathrm{ml}$ of hexane, then $0.1 \mathrm{ml}$ of a sodium methylate solution in methanol at a concentration of $2 \mathrm{~mol} / \mathrm{l}$ was introduced and stirred vigorously for $2 \mathrm{~min}$, settled for $5 \mathrm{~min}$ and filtered through a paper filter.

Pour point, density, relative viscosity, and flash point (open-cup) of the additive were determined in accordance with the requirements of the standards [1619]. The average molecular weight of the additive was determined by a cryoscopy.

\subsubsection{The method for checking the additive effect on the aggregative stability of fuel oil}

Phase imbalance in a system containing paraffin components was evaluated by the stability factor of pure fuel oil and fuel oil with additive using a colorimetric method. Test tubes containing $4 \mathrm{ml}$ of pure fuel oil and fuel oil with additive $(0.1,0.3$ and $0.5 \mathrm{wt} \%)$ were used. Since the application of the colorimetric method is impossible for pure fuel oil due to its high viscosity and optical density, $6 \mathrm{ml}$ of the mixture consisting of toluene, which was used as a solvent and $n$-hexane, which was used for the precipitation of asphaltenes, in a ratio of 7:3 were added to every tube and mixed thoroughly. Centrifugation was performed on a Mechanika Precyzyjna laboratory centrifuge with a rotor speed of $6000 \mathrm{rpm}$ for 30 and $60 \mathrm{~min}$. After stopping, the upper and lower layers $(1 \mathrm{ml})$ were withdrawn and the optical density of each sample was determined on a ULAB 102 photoelectric spectrophotometer.

The stability factor was calculated by the formula [20]:

$$
F=\frac{D_{1}}{D_{2}}
$$

where $D_{1}$ and $D_{2}$ are optical density of the upper and lower layers, respectively.

\subsubsection{Methods for checking the depressant effect of the additive}

The depressant effect of the additive on the pour point of fuel oil was determined in accordance with the requirements of the standard [16]. Also, to determine the effect of additive on the operational characteristics of fuel oil, the change in its density, relative viscosity and flash point when adding the additive was determined [17-19]

The depressant effect of the additive on the rate of paraffin crystals formation was assessed by their real-time growth using a polarization microscopy [21]. The test samples were cooled to the temperature by $5 \mathrm{~K}$ below the pour point and the images of paraffin crystals formation 
were recorded every $12 \mathrm{~s}$. The process was investigated using an optical microscope UlabXSP-137TLED, equipped with two linearly polarized lenses (the polarizer lens was in the socket for the light filter and the analyzer lens was under the camera lens).

The share of the image area occupied by paraffin crystals was calculated using the program ImageJ. Since the thickness of the samples between the object-plate and cover glass was much smaller than the area occupied by the paraffin crystals, their surface share in the images was equated to their volumetric content. The technique used allowed to identify paraffin crystals, to observe the realtime change in their size, as well as to evaluate the effect of temperature.

\section{Results and Discussion}

\subsection{Characteristics of the Synthesized Additive}

The synthesized additive is a viscous yellow liquid. Its physico-chemical characteristics is represented in Table 1.

Table 1

\section{Physico-chemical characteristics of the synthesized additive}

\begin{tabular}{|l|c|}
\hline \multicolumn{1}{|c|}{ Index } & Value \\
\hline Density at $293 \mathrm{~K}, \mathrm{~kg} / \mathrm{m}^{3}$ & 933.3 \\
\hline Relative viscosity at 313 K & 8.89 \\
\hline Relative viscosity at $373 \mathrm{~K}$ & 1.96 \\
\hline Viscosity index & 167 \\
\hline Average molecular weight, $\mathrm{kg} / \mathrm{kmol}$ & 625.7 \\
\hline Flash point (open-cup), K & 378 \\
\hline Pour point, K & 267 \\
\hline
\end{tabular}

The chromatographic analysis results of the quantitative composition of the additive acid residues are represented in Fig. 1.

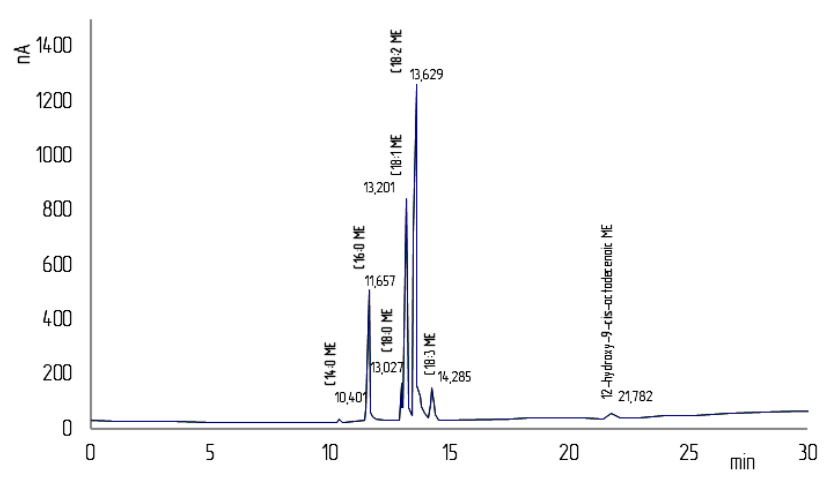

Fig. 1. Chromatogram of the synthesized additive
According to Fig. 1, the content of diglycerides of acids was as follows: palmitic acid (C16:0) $-9.42 \%$, stearic acid (C18:0) - 4.236\%, oleic acid (C18:1) $28.23 \%$, linoleic acid (C18:2) - 50.84\%, linolenic acid (C18:3) - 5.283\%, ricinoleic acid (12-hydroxy-9-cisoctadecenoic acid) - $1.941 \%$ and impurities of diglycerides of myristic acid (C14:0) $-0.051 \%$.

\subsection{Algorithm for Creating a Mathematical Model for Predicting Phase Transitions}

To predict the regularities of phase transitions of paraffinic hydrocarbons in petroleum dispersed systems with the decreasing temperature and their change when adding an additive, a mathematical model for thermodynamic calculations of PDS properties was developed based on the values of equilibrium constants of the hydrocarbon mixture components. The constants were determined as the ratio of the $i$-th component molar fraction in the solid phase to the molar fraction of this component in the liquid phase and characterized the distribution of the mixture $i$-th component between solid and liquid phase:

$$
K_{i}=\frac{\theta_{i}}{\chi_{i}}
$$

where $\theta_{i}$ is the molar fraction of the $i$-th component in the solid phase; $\chi_{i}$ is the molar fraction of the $i$-th component in the liquid phase.

The system is in equilibrium at a given temperature $T$, under the condition that the chemical potential of the component in the solid phase is equal to the potential of this component in the liquid phase:

$$
K_{i}=e^{\frac{\mu_{i}^{(S)}-\mu_{i}^{(L)}}{R T}}
$$

where $\mu_{i}^{(S)}$ and $\mu_{i}^{(L)}$ are the chemical potentials of the component in the solid and liquid phases, respectively; $R$ is the universal gas constant equal to $8.314 \mathrm{~J} /(\mathrm{mol} \cdot \mathrm{K}) ; T$ is an ambient temperature, $\mathrm{K}$.

The relationship between chemical potentials and fugitives of pure compound in the solid $\left(f_{i}^{(S)}\right)$ and liquid $f_{i}^{(L)}$ phases was described by Eq. (4):

$$
\mu_{i}^{(S)}-\mu_{i}^{(L)}=R T \ln \left(\frac{f_{i}^{(S)}}{f_{i}^{(L)}}\right)
$$

Combining Eqs. (3) and (4), we obtained:

$$
K_{i}=\frac{f_{i}^{(S)}}{f_{i}^{(L)}}
$$

To correct the activities deviation of the system components in the real conditions in the equilibrium state the additional factors were introduced into Eq. (5): 


$$
K_{i}=\frac{f_{i}^{(S)}}{f_{i}^{(L)}} \cdot \frac{\gamma_{i}^{(S)}}{\gamma_{i}^{(L)}}
$$

where $\gamma_{i}^{(S)}$ and $\gamma_{i}^{(L)}$ are the coefficients of activity of the $i$-th component in the solid and liquid phases in real conditions, respectively.

The ratio of fugitives was determined from the general concepts of molecular thermodynamics (Clapeyron-Clausis equation) [22].

$$
\begin{gathered}
\ln \left(\frac{f_{i}^{(S)}}{f_{i}^{(L)}}\right)=\left\{\frac{\Delta h_{i}^{f}}{R T}\left[1-\frac{T}{T_{i}^{f}}\right]+\right. \\
\left.+\frac{\Delta c_{p i}}{R}\left[1-\frac{T_{i}^{f}}{T}+\ln \left(\frac{T_{i}^{f}}{T}\right)\right]\right\} \cdot \frac{M_{i}}{1000}
\end{gathered}
$$

where $\Delta h_{i}^{f}$ is the specific enthalpy of the phase transition of the $i$-th component from the liquid phase to the solid one, $\mathrm{J} / \mathrm{kg} ; T_{i}^{f}$ is a phase transition temperature of the $i$-th component, $\mathrm{K} ; \Delta C_{p i}$ is a change in heat capacity of the $i$-th component during the phase transition, $\mathrm{J} /(\mathrm{kg} \cdot \mathrm{K}) ; M_{i}$ is a molar weight of the $i$-th component, $\mathrm{kg} / \mathrm{kmol}$.

Taking into account the existence of two allotropic forms of paraffin crystals (fibrous and lamellar), Eq. (7) took the form:

$$
\begin{aligned}
& \ln \left(\frac{f_{i}^{(S)}}{f_{i}^{(L)}}\right)=\left\{\frac{\Delta h_{i}^{f}}{R T}\left[1-\frac{T}{T_{i}^{f}}\right]+\frac{\Delta h_{i}^{t}}{R T}\left[1-\frac{T}{T_{i}^{t}}\right]-\right. \\
& \left.-\frac{1}{R T} \int_{T}^{T_{i}^{f}} \Delta c_{p i} d T+\frac{1}{R} \int_{T}^{T_{i}^{f}} \frac{\Delta c_{p i}}{T} d T\right\} \cdot \frac{M_{i}}{1000}
\end{aligned}
$$

where $\Delta h_{i}^{t}$ is the specific enthalpy of allotropic transformation of the $i$-th component from fibrous to lamellar form, $\mathrm{J} / \mathrm{kg} ; T_{i}^{t}$ is a temperature of allotropic transformation of the $i$-th component, $\mathrm{K}$;

To obtain the constants included in Eq. (8), we used correlation dependences for each component of the mixture. To determine $T_{i}^{f}$ the Won's coefficients [23] were used:

$$
\begin{gathered}
T_{i}^{f}=374.5+0.02617 M_{i}-\frac{20172}{M_{i}} \\
\text { for } M_{i} \leq 450 \mathrm{~kg} / \mathrm{kmol} \\
T_{i}^{f}=411.4-\frac{32326}{M_{i}} \text { for } M_{i}>450 \mathrm{~kg} / \mathrm{kmol}
\end{gathered}
$$

Specific enthalpy of phase transition of hydrocarbons [24]:

$$
\Delta h_{i}^{f}=-209.3-163.3 M_{i}
$$

To estimate the temperature and enthalpy of allotropic transformation of the lamellar form of the $i$-th component into the fibrous one we used the following equations [7]:
For unpaired hydrocarbons having from 7 to 49 carbon numbers:

$$
\begin{aligned}
& T_{i}^{t}=0.0039 n C_{i}^{3}-0.425 n C_{i}^{2}+17.28 n C_{i}+93.1 \\
& \Delta h_{i}^{t}=39805-6180.1 n C_{i}+347.9 n C_{i}^{2}-4.96 n C_{i}^{3}
\end{aligned}
$$

For paired hydrocarbons having from 6 to 50 carbon atoms:

$$
\begin{aligned}
& T_{i}^{t}=0.0032 n C_{i}^{3}-0.325 n C_{i}^{2}+12.78 n C_{i}+157.2 \\
& \Delta h_{i}^{t}=44019.6-6181.7 n C_{i}+348.7 n C_{i}^{2}-4.96 n C_{i}^{3}
\end{aligned}
$$

where $n C_{i}$ is the number of carbon atoms in the $i$-th component.

To estimate the change in a heat capacity during melting of the $i$-th component, we chose the Pedersen correlation $[9,25]$ :

$$
\Delta c_{p i}=0.3033 M_{i}-4.635 \cdot 10^{-4} M_{i} T
$$

The ratio of the activity coefficients of the liquid and solid phases was calculated according to the correlation proposed by Won [24]:

$$
\frac{\gamma_{i}^{(S)}}{\gamma_{i}^{(L)}}=e^{\left[\frac{V_{i}^{(S)}}{R T} \cdot\left(\delta_{m}-\delta_{i}\right)_{S}^{2}-\frac{V_{i}^{(L)}}{R T} \cdot\left(\delta_{m}-\delta_{i}\right)_{L}^{2}\right]}
$$

where $V_{i}^{(S)}$ and $V_{i}^{(L)}$ are the molar volumes of the $i$-th component in the solid and liquid phases, respectively; $\delta_{i}$ is the solubility parameter of the $i$-th component, $\left(\mathrm{kJ} / \mathrm{m}^{3}\right)^{0.5} ; \delta_{m}$ is the average solubility parameter of the phase, $\left(\mathrm{kJ} / \mathrm{m}^{3}\right)^{0.5}$.

The molar volume of the $i$-th component in the liquid phase was calculated by the Chang correlation [26]:

$$
V_{i}^{(L)}=3.8 \cdot M_{i}^{0,786}
$$

The molar volume of the $i$-th component in the solid phase was expressed as [24]:

$$
V_{i}^{(S)}=V_{i}^{(L)}-0.17 \cdot M_{i}
$$

Solubility parameters characterize the intermolecular interaction in a liquid and solid body.

The solubility parameters of the $i$-th component in the solid and liquid phases were calculated by correlation $[9,25]$ :

$$
\begin{aligned}
\delta_{i}^{s} & =17.399+11.797 \cdot\left(\ln n C_{i}-\ln 7\right) \\
\delta_{i}^{L} & =15.168+1.211 \cdot\left(\ln n C_{i}-\ln 7\right)
\end{aligned}
$$

The average solubility parameter for each phase was found in accordance with the rule of additivity:

$$
\delta_{m}=\sum \delta_{i} \varphi_{i}
$$

where $\varphi_{i}$ is the volume fraction of the $i$-th component in this phase.

$$
\varphi_{i}=\frac{V_{i} \chi_{i}}{\sum V_{i} \chi_{i}}
$$

Thus, the joint solution of Eq. (8), which describes the effect of the components fugitives and the correlation (17), which describes the influence of the components 
activities on the state of the system, the resulting equation took the form:

$$
\left.K_{i}=\exp \left(\begin{array}{l}
\left\{\frac{\Delta h_{i}^{f}}{R T} \cdot\left(1-\frac{T}{T_{i}^{f}}\right)-\frac{\Delta h_{i}^{t}}{R T} \cdot\left(1-\frac{T}{T_{i}^{t}}\right)-\frac{0,3033 M_{i}}{R}\left(\frac{T_{i}^{f}}{T}-1-\ln \frac{T_{i}^{f}}{T}\right)-\right. \\
-\frac{4,635 \cdot 10^{-4} M_{i}}{2 R} \cdot\left[\frac{\left(T_{i}^{f}\right)^{2}}{T}-1-2 T_{i}^{f}\right] \\
+\frac{V_{i}^{(S)}}{R T} \cdot\left(\delta_{m}-\delta_{i}\right)_{s}^{2}-\frac{V_{i}^{(L)}}{R T} \cdot\left(\delta_{m}-\delta_{i}\right)_{L}^{2}
\end{array}\right\}+\right)
$$

After calculating the phase equilibrium constants using the above mentioned model, the composition of the solid phase was determined by the following equations:

$$
\sum \chi_{i}=\sum \frac{z_{i}}{1+\bar{n}_{s}\left(K_{i}-1\right)}=1
$$

where $z_{i}$ is the molar fraction of the $i$-th component in the system; $\bar{n}_{S}$ is a total molar fraction of the solid phase.
The material balance for the $i$-th component was determined by Eq. (26):

$$
\sum \theta_{i}=\sum z_{i} \cdot K_{i}=1
$$

Equation (25) was solved by an iterative method in respect to $\bar{n}_{S}$. The values $\bar{n}_{S}$ were selected if Eq. (26) was valid. Thus the amount of solid phase was determined.

As can be seen from Eq. (17), to shift the interfacial equilibrium "solid-liquid" in the petroleum dispersion system towards the liquid, it is necessary to reduce the ratio of activities of the solid to a liquid phase. To do this, it is advisable to introduce into system the compounds that have a much lower solubility parameter than hydrocarbons. Such compounds were diglycerides of fatty acids [27]. A comparison of their solubility parameters with those of hydrocarbons calculated by Eqs. (20) and (21) is shown in Table 2.

Table 2

Comparison of solubility parameters of $\boldsymbol{n}$-alkanes and diglycerides of fatty acids

\begin{tabular}{|l|c|c|}
\hline \multicolumn{1}{|c|}{ Formula or name of the compound } & \multicolumn{2}{c|}{ Solubility parameter, $\left(\mathrm{kJ} / \mathrm{m}^{3}\right)^{0.5}$} \\
\cline { 2 - 3 } & in liquid phase & 28.54 \\
\hline$n-\mathrm{C}_{18} \mathrm{H}_{38}$ & 16.311 & 30.908 \\
\hline$n-\mathrm{C}_{22} \mathrm{H}_{46}$ & 16.554 & 34.566 \\
\hline$n-\mathrm{C}_{30} \mathrm{H}_{62}$ & 16.93 & 37.96 \\
\hline$n-\mathrm{C}_{40} \mathrm{H}_{82}$ & 17.278 & 17.4 \\
\hline Diglyceride of oleic acid & 11.6 & 17.85 \\
\hline Diglyceride of linoleic acid & 11.9 & 16.22 \\
\hline Diglyceride of linolenic acid & 10.81 & 16.23 \\
\hline Diglyceride of ricinoleic acid & 10.82 & \\
\hline
\end{tabular}

To implement the calculations of the phase equilibrium of petroleum dispersed systems, a software product was created, the algorithm of which included the following stages:

- input of initial data;

- approximation of PDS fractional composition with a hypothetical paraffin mixture;

- calculation of test values of phase equilibrium constants without taking into account the activity coefficients of the components for a given temperature range;

- iterative finding of more exact values of phase equilibrium constants;

- determining the amount of solid phase;

- recalculation of the hypothetical mixture composition with the addition of additives;

- repetition of the iterative part of the calculation.

According to the algorithm of the created mathematical model, the pour point of pure fuel oil and its mixture with additive $(0.1,0.3$ and $0.5 \mathrm{wt} \%)$ was calculated.The example of the diagram to calculate the solid phase formation in fuel oil samples before and after adding $0.3 \mathrm{wt} \%$ of additive depending on the temperature is shown in Fig. 2.

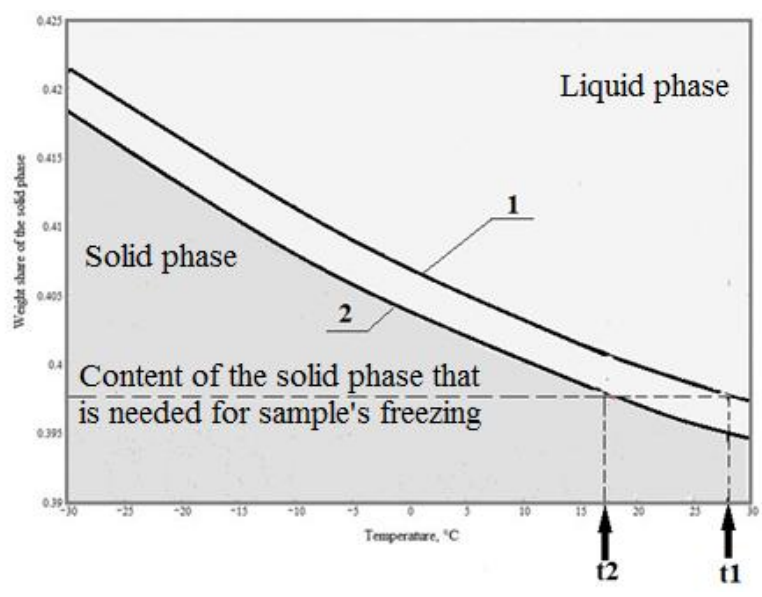

Fig. 2. Diagram of solid phase formation in the samples of pure fuel oil (1) and fuel oil with $0.3 \mathrm{wt} \%$ of additive (2) depending on the temperature: $\mathrm{t} 1$ and $\mathrm{t} 2$ are pour points of fuel oil and its mixture with the additive, respectively 
We assume that for solidification the VAT sample requires the accumulation of a certain critical amount of solid phase. Solidification of pure fuel oil is observed at $301 \mathrm{~K}$, which corresponds to the amount of solid phase 39.8 wt \% (Fig. 2). When adding the synthesized additive, a similar amount of solid phase is formed at $290 \mathrm{~K}$, which indicates a decrease in the pour point of fuel oil by $11 \mathrm{~K}$.

To verify the results of the model, we experimentally determinated the pour point of fuel oil with an additive. Comparison of the experimental and calculated results and compliance of the main physical and chemical parameters with the standards are given in Table 3.

As can be seen from Table 3, the addition of $0.3 \mathrm{wt} \%$ of vegetable additive allowed to reduce the pour point of fuel oil by $12 \mathrm{~K}$ (deviation from the calculated value was $1 \mathrm{~K}$ ). The values of density, relative viscosity and flash point of all test samples meet regulatory requirements.

Table 3

\section{Physico-chemical characteristics of experimental samples of fuel oil with an additive}

\begin{tabular}{|c|c|c|c|c|c|}
\hline \multirow{2}{*}{ Sample } & \multicolumn{2}{|c|}{ Pour point, $\mathrm{K}$} & \multirow{2}{*}{$\begin{array}{c}\text { Density at } 293 \mathrm{~K}, \\
\mathrm{~kg} / \mathrm{m}^{3}\end{array}$} & \multirow{2}{*}{$\begin{array}{c}\text { Relative } \\
\text { viscosity at } \\
353 \mathrm{~K}\end{array}$} & \multirow{2}{*}{$\begin{array}{c}\text { Flash point } \\
\text { (open-cup), } \mathrm{K}\end{array}$} \\
\hline & Model & Experiment & & & \\
\hline Fuel oil $+0.1 \mathrm{wt} \%$ additive & 294 & 290 & 886.2 & 1.98 & 426 \\
\hline Fuel oil + $0.3 \mathrm{wt} \%$ additive & 290 & 289 & 886.3 & 1.96 & 426 \\
\hline Fuel oil $+0.5 \mathrm{wt} \%$ additive & 292 & 291 & 886.5 & 1.91 & 424 \\
\hline Fuel oil (control sample) & - & 301 & 886.2 & 2.21 & 428 \\
\hline Fuel oil M100 [28] & \multicolumn{2}{|c|}{$\max 298$} & $\begin{array}{c}900-1100 \\
\text { (recommended) }\end{array}$ & $\max 16.0$ & $\min 110$ \\
\hline
\end{tabular}

Table 4

Results of photocolorimetric studies

\begin{tabular}{|c|c|c|c|c|}
\hline \multirow{2}{*}{ Sample } & \multirow{2}{*}{ Centrifugation time, $\min$} & \multicolumn{2}{|c|}{$\begin{array}{l}\text { Optical density of cetrifugate at } \\
\qquad \lambda=700 \mathrm{~nm}\end{array}$} & \multirow{2}{*}{ Stability factor } \\
\hline & & Upper layer & Bottom layer & \\
\hline Fuel oil & \multirow{2}{*}{30} & 2.018 & 2.078 & 0.971 \\
\hline Fuel oil $+0.3 \mathrm{wt} \%$ additive & & 2.333 & 2.331 & 1.000 \\
\hline Fuel oil & \multirow{2}{*}{60} & 1.804 & 1.895 & 0.953 \\
\hline Fuel oil $+0.3 \mathrm{wt} \%$ additive & & 2.106 & 2.124 & 0.991 \\
\hline
\end{tabular}

The effectiveness of the additive on the phase equilibrium and stability of fuel oil and its mixture with $0.3 \mathrm{wt} \%$ of additive based on the results of photocolorimetric studies are presented in Table 4.

As can be seen from Table 4, the value of the stability factor of the fuel oil with the additive is close to unity, which confirms the effectiveness of the additive as a paraffin inhibitor.

Visual analysis of the dynamics of paraffin crystal formation in the samples of pure fuel oil and its mixture with the additive recorded by a microscope after 12, 60 and $456 \mathrm{~s}$ are shown in Fig. 3. The bright spots in the photo correspond to paraffin crystals.

Analysis of the paraffin crystals growth in the samples of pure fuel oil (Fig. 3a) showed that over time there is an increase in the number of crystallization centers and their slight enlargement. The additive inhibits the formation of crystallization centers and their growth (Fig. $3 b)$. Due to the adsorption of carboxyl groups of palmitic, stearic, oleic, linoleic, linolenic and ricinoleic acids, which are part of the additive, the active centers of paraffin molecules change their structure, as evidenced by microphotos in Fig. 3c. The formed with paraffin mixed crystals disrupt the natural process of crystallization and inhibit it. The dispersing effect of the additive is valid at its concentration of up to $0.3 \mathrm{wt} \%$. When the additive content increases to $0.5 \mathrm{wt} \%$, the dissolving of small crystalline formations and moving of paraffinic material to larger ones are observed. So, the crystalline particles were larger. At the same time, the volume concentration of solid paraffin became higher. 
The results obtained for each sample were approximated by a kinetic equation of the following type [29]:

$$
\varphi=\frac{A \cdot \tau}{B+\tau} \cdot \exp \left(\frac{-C}{\Delta T^{2}}\right)
$$

where $\varphi$ is the content of paraffin crystals, vol $\% ; \tau$ is time, $\mathrm{s} ; \Delta T$ is an overcooling temperature of the sample, ${ }^{\circ} \mathrm{C}$; A, B, C are coefficients selected by the iteration method under the condition of better agreement with the experimental data.

The results of mathematical processing of microphotos with the determination of the change in the volume content of the solid phase as a function of time under experimental conditions were compared with the approximation data of the kinetic equation (27) and summarized in Fig. 4.

As can be seen from Fig. 4, the rate of paraffin crystals formation is the greatest in the initial period of time (up to $2 \mathrm{~min}$ ), after which the process slows down significantly. $0.3 \mathrm{wt} \%$ of the additive reduces the volume concentration of paraffin crystals by $\sim 20 \%$. The increase in the additive content to $0.5 \mathrm{wt} \%$ during the same time is accompanied by a depressant effect, but the concentration of paraffin crystals decreased by only $\sim 11 \%$.

Theoretical calculations of the kinetics of changes in the paraffin crystals volume content during fuel oil overcooling are in a good agreement with the results of experiments (correlation coefficients is in the range of $0.86-0.98)$.

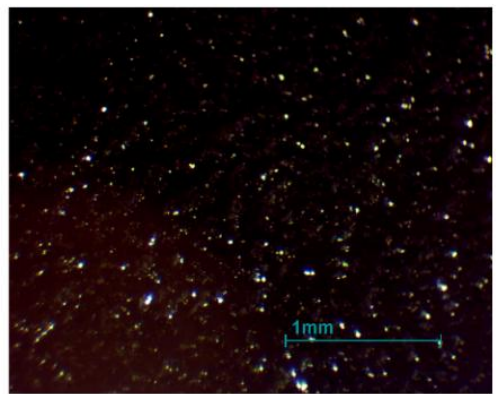

$12 \mathrm{~s}$

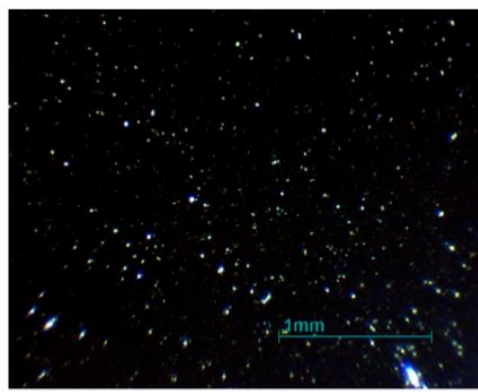

$12 \mathrm{~s}$

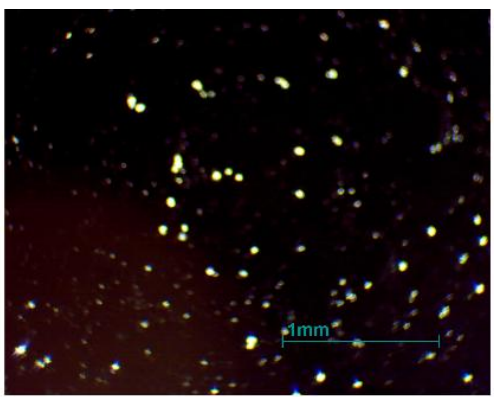

$12 \mathrm{~s}$

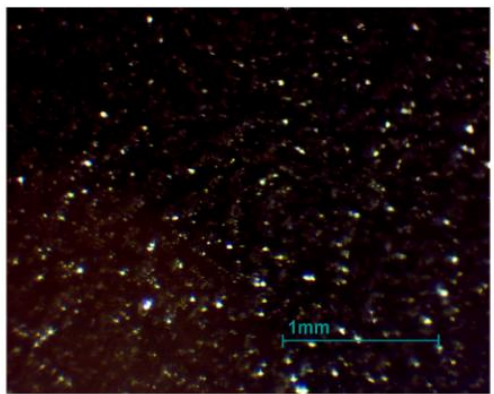

$60 \mathrm{~s}$

a)

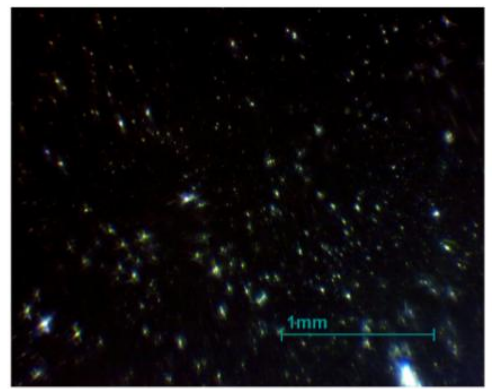

$60 \mathrm{~s}$

b)

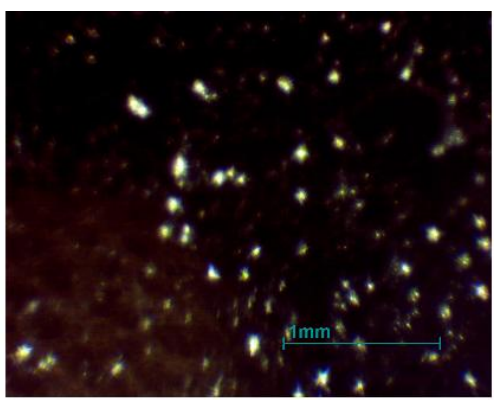

$60 \mathrm{~s}$

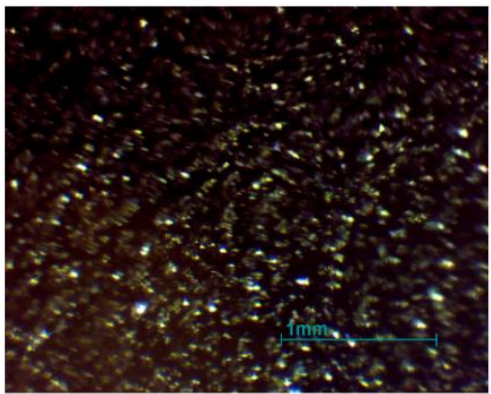

$456 \mathrm{~s}$

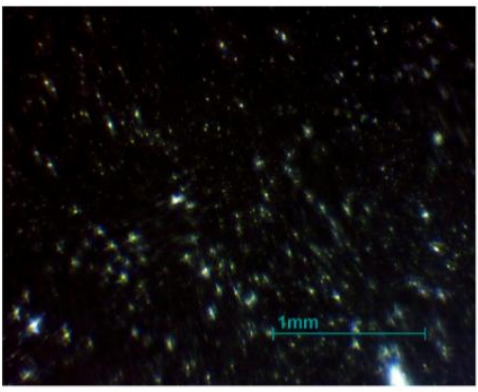

$456 \mathrm{~s}$

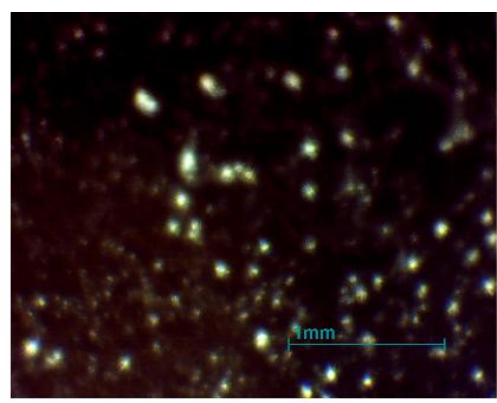

$456 \mathrm{~s}$

c)

Fig. 3. Dynamics of paraffin crystals growth in pure fuel oil (a); fuel oil with $0.3 \mathrm{wt} \%$ (b) and 0.5 wt $\%$ of additive 


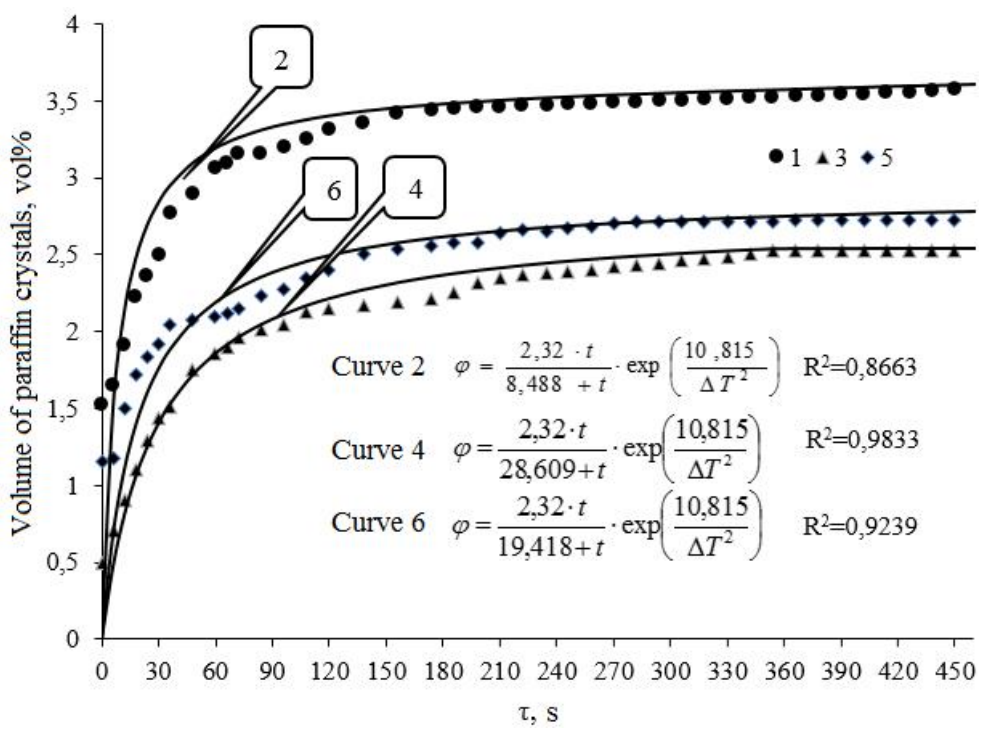

Fig. 4. Kinetic curves of the change in the volume content of paraffin crystals during overcooling of fuel oil.

Kinetic curves (experimental): pure fuel oil (1); fuel oil $+0.3 \mathrm{wt} \%$ of additive (3) and fuel oil $+0.5 \mathrm{wt} \%$ of additive (5).

Kinetic curves (approximation): pure fuel oil (2); fuel oil $+0.5 \mathrm{wt} \%$ of additive (4) and fuel oil $+0.3 \mathrm{wt} \%$ of additive (6)

\section{Conclusions}

A mathematical model for thermodynamic calculations of two-phase equilibrium in the "solid phaseliquid" system was developed, which allowed to predict the quantitative and qualitative composition of the solid phase (paraffin) in fuel oil depending on the temperature. Solidification of experimental samples of fuel oil occurs at a minimum amount of solid phase of $39.8 \mathrm{wt} \%$.

The depressant additive was synthesized on the basis of raw materials of plant origin; the qualitative and quantitative composition of the additive acid residues was determined.

It was found that the shift of phase equilibrium "solid-liquid" in the petroleum dispersed system towards the liquid was provided by the introduction into the system of a compound with a lower solubility parameter than that of hydrocarbons.

It was confirmed that addition of $0.3 \mathrm{wt} \%$ of the synthesized additive provided a reduction in the pour point of fuel oil by $12 \mathrm{~K}$ and increased its stability.

Comparison of theoretical and experimental results of crystalline phase formation kinetics showed that the proposed mathematical model allows to predict the process of paraffin formation in petroleum dispersed systems and evaluate the effectiveness of depressant inhibitors.

\section{References}

[1] Pylypiv L.: Naftohazova Enerhetyka, 2013, 1, 60.

[2] Rojenko K., Tertyshna O., Snizhko L. et al.: Naftohazova Haluz Ukrainy, 2014, 2, 24.

[3] Ivanova L., Burov E., Koshelev V.: Neftegazovoe Delo, 2011, 1, 268.

[4] Reistle C.: Paraffin and Congealing-Oil Problems. G.P.O.,

Washington 1932.

[5] Musakaev N.: Proceedings of International Conference RDAMM2001, Russia, Novosybirs'k 2001, 6-2, 318.

[6] Sharafutdinov R.: Prikladnaia Mechanika i Technicheskaia Fizika, 2001, 2, 111.

[7] Brusilovskyj A.: Fazovye Prevrashchenia pry Razrabotke Mestorozhdenyi Nefti i Gaza. Graal, Moskva 2002.

[8] Ortega-Rodriguez A., Cruz S., Gil-Villegas A. et al.: Energ. Fuel, 2003, 17, 1100. https://doi.org/10.1021/ef030005s

[9] Pedersen K., Skovborg P., Ronningsen H.: Energ. Fuel, 1991, 5, 924. https://doi.org/10.1021/ef00030a022

[10] Ghanaei E., Esmaeilzadeh F., Fathi Kaljahi F.: Int. J. Chem. Mol. Eng., 2007, 1, 48.

[11] Moiseev I.: Uspechi Khimii, 2013, 82, 616.

[12] Maksymuk Ju., Buhlak A., Kruk V. et al.: Khimia i Technologia Topliv i Masel, 2013, 3, 9.

[13] Maksymuk Ju., Buhlak A., Kruk V. et al.: Khimia i Technologia Topliv i Masel, 2013, 2, 12.

[14] Shabarov Ju.: Organicheskaia Khimia. Khimia, Moskva 2010.

[15] http://docs.cntd.ru/document/gost-30418-96

[16] https://www.astm.org/DATABASE.CART/HISTORICAL/D9709.htm

[17] http://online.budstandart.com/ua/catalog/doc-page?id_doc $=65853$

[18] http://docs.cntd.ru/document/1200122881

[19] http://docs.cntd.ru/document/gost-4333-87

[20] Tertyshna O., Royenko K., Martynenko V. et al.: Chem. Chem. Technol., 2016, 10, 361. https://doi.org/10.23939/chcht10.03.361 
[21] Zougari M., Sopkow T.: Ind. Eng. Chem. Res., 2007, 46, 1360. https://doi.org/10.1021/ie061002g

[22] Sivuchin D.: Obshchyi Kurs Fiziky. Tom II. Termodynamica i Molekuliarnaia Fizika. Nauka, Moskva 1990.

[23] Won K.: Fluid Phase Equilib., 1986, 30, 265.

https://doi.org/10.1016/0378-3812(86)80061-9

[24] Won K.: Fluid Phase Equilib., 1989, 13, 377.

https://doi.org/10.1016/0378-3812(89)80104-9

[25] Murgich J., Merino-Garcia D., Andersen S. et al.: Langmuir, 2002, 18, 9080. https://doi.org/10.1021/la025882p

[26] Chung T.-H.: SPE $67^{\text {th }}$ Annual Technical Conference and Exhibition. USA, Washington 1992, 869.

https://doi.org/10.2118/24851-MS

[27] Tertyshnay E., Martynenko V., Gyrenko A. et al.: SOCAR

Proceedings, 2018, 1, 52. https://doi.org/10.5510/OGP20180100340

[28] http://online.budstandart.com/ua/catalog/doc-

page?id doc $=70773$

[29] Markin A., Suchoverchov S.: Vestnik DVO Ros. Akad. Nauk, $2011,5,66$.

Received: September 26, 2019 / Revised: October 13, 2019 / Accepted: January 12, 2020

\section{ФАЗОВА РІВНОВАГА НАФТОВИХ ДИСПЕРСНИХ СИСТЕМ 3 ПОЗИЦІї ТЕРМОДИНАМІКИ ТА КІНЕТИКИ}

Анотація. Розглянуто процес парафіноутворення, включаючи особливості будови парафінів, внаслідок фазових переходів при зниженні температури. Розроблено математичні моделі термодинамічних $i$ кінетичних розрахунків фазової рівноваги системи “тверде тіло-рідина". Встановлено, щчо для змімення рівноваги “мазут-парафін” до рідини необхідно зменшити відношення активностей твердої і рідкої фаз за допомогою введення в систему речовини з меншим параметром розчинності. Синтезовано додаток рослинного походження для підвищення стійкості і структурно-механічних характеристик мазуту. Досліджено фазові переходи в мазуті в залежності від температури при додаванні різної кількості додатку.

Ключові слова: фазова рівновага, математична модель, термодинаміка, кінетика, додаток, мазут, парафін, кристали. 